\title{
CLÍNICA, A INTERPRETAÇÃO PSICANALÍTICA E O CAMPO DE EXPERIMENTAÇÃO
}

\author{
Leonardo Pinto de Almeida* \\ Raul Marcel Filgueiras Atallah"
}

\begin{abstract}
RESUMO. O presente trabalho se propõe a questionar se o método de interpretação na clínica psicanalítica pressupõe relações de poder que engessam a experiência clínica em valores universalizantes. Partindo das críticas de Deleuze, Guattari e Foucault à psicanálise, os autores concluíram que a prática da interpretação pode obliterar a experiência clínica, enquadrando-a em um ciclo de idéias universais e intimistas que apontam para a pressuposição de verdades instituídas pelos próprios conceitos psicanalíticos. Esta crítica indica que a clínica psicanalítica pode ser um campo de experimentação onde o sofrimento psíquico seria tratado sem priorizar a violência interpretativa.
\end{abstract}

Palavras-chave: clínica psicanalítica, interpretação, campo de experimentação.

\section{CLINIC, THE PSYCHOANALYTICAL INTERPRETATION AND THE FIELD OF EXPERIENCE}

\begin{abstract}
The present paper aims to question if the method of interpretation in the psychoanalytical clinic presuppose relations of power that can imprison the clinical experience in universals values. Leaving with the criticism of Deleuze, Guattari and Foucault to the psychoanalysis, the authors had concluded that the practical of the interpretation can obliterate the clinical experience fitting it in a cycle of universal and intimist ideas that points to presupposition of truths instituted by the proper psychoanalytical concepts. This criticism indicates that the psychoanalytical clinic can be an experimentation field where the psychic suffering would be treated without prioritizing the interpretative violence.
\end{abstract}

Key words: Psychoanalytical clinic, interpretation, field of experience.

\section{CLÍNICA, LA INTERPRETACIÓN PSICOANALÍTICA Y EL CAMPO DE LA EXPERIENCIA}

RESUMEN. El presente artículo se propone a la pregunta si el método de interpretación en la clínica psicoanalítica presupone exp relaciones del poder que encarcelan la experiência clínica en valores universales. Pensando en la crítica de Deleuze, de Guattari y de Foucault a la psicoanálisis, los autores concluyeron que la práctica de la interpretación puede borrar la experiencia clínica en un ciclo de ideas universales e intimistas que apuntan a la presuposición de verdades experiência por los propios conceptos psicoanalíticos. Esta crítica indica que la clínica psicoanalítica puede ser un campo de la experimentación donde el sufrimiento psíquico sería tratado sin dar la prioridad a la experiencia interpretativa.

Palabras-clave: Clínica psicoanalítica, interpretación, campo de la experiência.

O presente artigo tem como proposta colocar em questão a interpretação na técnica psicanalítica, cuja função clínica, nos dias atuais, é imprescindível analisarmos dentro do campo teórico derivado dos princípios estabelecidos por Freud em suas construções teóricas.
Para entendermos as condições para o aparecimento da noção de interpretação na teoria freudiana e suas nuanças conceituais precisamos, inicialmente, revisar os fundamentos da psicanálise, além de identificar suas modificações ao longo da construção teórica de Freud.

\footnotetext{
* Graduado em Psicologia. Mestre em Psicologia. Doutor em Psicologia. Pesquisador da Cátedra UNESCO de Leitura PUC-Rio de Janeiro.

\# Graduado em Psicologia. Mestre em Psicologia. Professor do Instituto de Psicologia e Psicanálise da Universidade Santa Úrsula.
} 
A psicanálise fundamentou-se na aposta de que a cura de um sofrimento psíquico poderia ser conduzida pela palavra. Freud, ao longo de sua obra, sempre sustentou que uma cura psicanalítica deveria ser feita dando-se inteligibilidade aos conteúdos de memória trazidos pelos pacientes. Esses conteúdos eram comunicados pela fala ao analista, ao qual caberia ajudar a rememorar e reconstruir esse material, como meio de chegar às causas do sofrimento psíquico. A causa desse sofrimento teria uma origem específica, que seria um trauma real ou fantasiado, ao qual se deveria ter acesso pela análise e interpretação dos sintomas, reconectando-o à sua origem.

Freud apostou na teoria de que, ao fazer retornar à consciência dos seus pacientes uma lembrança desagradável, estes poderiam ser capazes de ressignificar o material ideativo que produziria os sintomas, dando-lhe outro sentido simbólico. Mas as lembranças estavam presentes de outra forma, não pela racionalização, mas por manifestações corporais ou ideativas que produziam os sintomas clínicos. Freud, com seu método de investigação analítica, tentou ir à origem das neuroses, às suas causas primeiras, e reconstruir o caminho percorrido pela história subjetiva de seus pacientes, a fim de estabelecer um entendimento e trazer à luz da consciência a origem subjetiva dos sintomas clínicos que ele observava.

Podemos dizer que o método psicanalítico freudiano revolucionou a clínica das neuroses até então conhecida. Esse método dava aos pacientes a possibilidade de significar seus sintomas e religá-los a uma história. Ao fazer isso, a psicanálise deslocou o entendimento puramente biológico das neuroses para uma posição em que eram levadas em consideração as construções simbólicas dos pacientes. Ao formular sua concepção de inconsciente, Freud rompeu com uma tradição filosófica dominante que valorizava a consciência e a racionalidade psíquica, fundando sua metapsicologia ${ }^{1}$. O inconsciente, em Freud, é algo que foge ao racional, mas não ao lógico, sendo passível de interpretação através de uma análise de seus simbolismos.

Ele considerava o inconsciente o lugar onde ficava impressa a história dos investimentos libidinais, que ao se frustrarem na realidade objetiva, retornavam

1 Em O Inconsciente, Freud (1915) mostra que o Inconsciente, como sistema do aparato psíquico, difere das outras concepções de inconsciente vigentes em sua época. A palavra inconsciente era usada adjetivamente por filósofos e médicos do seu tempo para designarem lacunas da consciência, elementos que se encontravam fora do foco da consciência. A novidade em Freud é o uso substantivo da palavra, já que ele transforma o Inconsciente em um sistema próprio, marcadamente, diferente da consciência. ao aparelho psíquico, recalcando-se. O objetivo de uma análise seria rememorar o recalcado, trazer entendimento e racionalidade ao material inconsciente e fazer com que os afetos que causavam o sofrimento psíquico fossem revividos e elaborados no momento presente.

A interpretação seria fundamental para o seu método analítico. A tradução dos signos ininteligíveis que apareciam num processo de rememoração analítica seria feita pela interpretação, que estabeleceria o sentido dos signos apresentados na clínica. Aqui chegamos ao ponto que apontamos como problema

A interpretação psicanalítica, como podemos notar em toda a obra freudiana, emprestou sentido, deu visibilidade, coordenou entendimentos e principalmente, fundou verdades sobre o modo de funcionamento do aparelho psíquico. Ela tornou-se a força primordial de comunicação, de estabelecimento de sentido, de condução da clínica, e também de toda uma rede de poder e saber entre psicanalista e paciente.

Freud, com seu método analítico, fundou um campo de embates que se estendem até nossos dias, entre a interpretação calcada em pressupostos teóricos rígidos e o discurso do inconsciente e do desejo. A rigidez interpretativa da clínica psicanalítica é aqui colocada em questão para podermos valorizar a interpretação não como imputação de sentido ou como forma rígida de entendimento de uma verdade subjetiva, mas como um campo onde se possa constituir a experimentação e o encontro com o novo. Para fundamentar a crítica ao método psicanalítico tradicional precisamos retomar alguns dos conceitos da metapsicologia freudiana e fundamentar algumas críticas possíveis, o que será feito nos próximos tópicos.

\section{METAPSICOLOGIA E A INTERPRETAÇÃO}

Ao montar o arcabouço teórico da metapsicologia, Freud fez algo mais que dar visibilidade aos processos mentais inconscientes: acabou criando uma unidade explicativa da vida mental baseada em conceitos que tentavam ser universais. Ele foi muito criticado por privilegiar determinadas formações inconscientes em detrimento de outras possíveis. O esforço para desenvolver um modelo explicativo das origens da subjetividade $^{2}$ no homem fez da teoria e da prática

\footnotetext{
2 Por subjetividade entendemos um campo de forças semióticas que são ao mesmo tempo coletivas e individualizantes, fundadores de sujeitos, de maneiras de ser e estar no mundo. Subjetividade é, portanto, para pensadores como Foucault Deleuze e Guattari, o produto singular de forças provenientes de diversas instâncias,
} 
clínica um amarrado conceitual inflado de sentido, onde a sugestão poderia estar mais presente do que ele mesmo imaginava.

A função da interpretação modificou-se ao longo da obra freudiana, a ponto de servir também para romper com as resistências dos pacientes ao processo analítico. Ao apontar as resistências em um discurso do paciente e nas demandas que esse provocava ao analista, Freud, mais do que fazê-los falar, demonstrava uma formalização em sua clínica que os poderia introduzir num sistema de construções de verdade ao qual os pacientes se submetiam. As interpretações psicanalíticas, nesse sentido, criavam um campo de conhecimento baseado nas suposições freudianas sobre a formação do desejo.

A releitura de Lacan (1996) trouxe à técnica psicanalítica ares novos, mas não menos problemáticos. Ao trazer a lingüística estrutural para a questão psicanalítica, conseguiu deslocar a visão ontológica do inconsciente de Freud para um universo ético da linguagem.

O privilégio do inconsciente como instância mediadora do sujeito com os objetos é característico da teoria lacaniana. Aos objetos só teríamos acesso pela representação significante, mediado pelas leis da linguagem. O objeto em si, ao qual o sujeito se dirigiria, estaria perdido na entrada no universo simbólico do desejo.

Lacan não privilegia nas interpretações o resgate histórico do sujeito, nem valoriza as imputações de sentido do analista para com o analisando. As construções em análise não objetivavam uma estruturação do eu, mas dariam privilégio ao simbólico e ao desfile dos significantes dos pacientes em sua fala. Fazê-los falar era mais importante, e o analista permanecia no lugar de sujeito faltoso. $\mathrm{Na}$ falta do analista, o paciente fala e interpreta por si mesmo. A não-fala do analista, mesmo que não signifique seu silêncio objetivo, coloca-o na posição de testemunha dos sintomas, ao qual o paciente deve dirigir-se como se falasse para uma figura mítica, que tudo sabe, mas nada diz. A interpretação não é uma fala do analista, é do dito do paciente que a interpretação advém. Mas se o sentido é dado sempre pelo sujeito, como fica a linguagem em sua perspectiva de acontecimento entre dois? Se uma análise não é um monólogo, a quem se dirige a fala do paciente? Não é ao analista, é ao grande Outro da linguagem. É aqui também que o inconsciente se produz.

sejam elas políticas, econômicas, sociais, históricas, capazes de fundar sujeitos e sua maneira de se relacionar com o mundo e consigo mesmo.
O inconsciente lacaniano é uma construção do presente, da relação intersubjetiva entre analista e paciente, sendo o simbólico o campo mediador dessa relação. $\mathrm{O}$ discurso que ali se produz tem um estatuto de verdade, embora seja sempre uma construção do presente. Renegou-se a história da verdade individual e a lançou em um a posteriori que sempre se ressignifica, mas que o faz segundo uma lei. Amarrado a esse universo simbólico, o sujeito comunica-se com o mundo.

Esse sistema explicativo da subjetividade humana tem uma conseqüência: aprisiona o sujeito a uma origem. $\mathrm{O}$ momento do recalcamento originário, como definido por Freud, seria o ponto de fundação de uma subjetividade calcada numa renúncia ao objeto primordial de desejo. Na experiência mítica da fundação do inconsciente, Freud pontuará que a renúncia ao incesto, colocada pela função paterna, produz uma marca que funda o desejo. As fantasias seriam produto de uma tentativa reparadora dessa marca deixada pela primeira experiência de renúncia a um objeto primeiro; ou seja, o recalque primeiro, que produz acesso à linguagem e à cultura, seria o processo de formação do inconsciente e do aparelho psíquico por uma negatividade, por uma falta estrutural.

Críticas a essa concepção de sujeito podem ser vistas nas obras de Deleuze, Guattari e Foucault, principalmente. Para esses autores, seguindo-se o pensamento nietzschiano, a visão de sujeito da psicanálise era reduzida e limitadora. Não estava presente a dimensão múltipla das determinações subjetivas, não havia nesse pensamento estruturalista a dimensão de produção da subjetividade, logo não era questionado que tipo de sujeito era produzido em uma análise.

A criação de modos de existir e a afirmação da diferença não estavam presentes nas teorias freudianas e lacanianas. Ao contrário, a afirmação constante da negatividade do desejo, ou seja, de apontar o desejo inconsciente como falta, produzia uma subjetividade sujeitada a uma formalidade subjetiva que de nada tinha de livre. Ao mergulhar-se nesse discurso, o que poderia advir com mais facilidade seria a resignação e a aceitação, caracterizando a falta como a impotência de mudança nos modos de existir. Deleuze, ao criticar a psicanálise lacaniana, afirma:

(...) a significância substituiu a interpretação, o significante substituiu o significado, o silêncio do analista substituiu seu comentário, a castração revelou-se mais certa do que Édipo, as funções estruturais substituíram a imagem dos progenitores, o 
nome do Pai substitui meu papai. Não vemos grandes mudanças na prática.(...)Por mais que nos digam: vocês não compreendem nada, Édipo não é papai e mamãe, é o simbólico, a lei, o acesso à cultura, é o efeito do significante, é a finitude o sujeito, é a "falta a ser que é a vida". E se não é Édipo, será a castração ou as pretensas pulsões de morte. Os psicanalistas ensinam a resignação infinita, são os últimos padres (não, haverão outros depois). (Deleuze, 1998, p. 97)

Poderíamos assim nos indagar: que tipo de discurso promove a clínica e que sujeitos ela produz? Tomemos a crítica à interpretação como ponto de partida para nossa reflexão.

Mesmo com inúmeros questionamentos ao método psicanalítico de Freud, percebemos, nos dias atuais, a permanência de técnicas e propostas clínicas amarradas a uma noção de subjetividade que é, em si, universalizadora e intimista. Muitas técnicas focadas na pessoalização da subjetividade provocam um fechamento do campo de conhecimento da psicanálise e de suas concepções de desejo baseado em uma negatividade. Há aqui uma notável visão do sujeito que o aprisiona a uma amarragem simbólica identitária, seja pela afirmação de um eu constante e imutável, seja por uma regra inconsciente que rege seu comportamento.

Para fazer frente aos questionamentos contemporâneos da clínica, faz-se necessário abrirmos a psicanálise para outros campos de saber. Ao combiná-la com outros instrumentos de inteligibilidade do sujeito, podemos criar novos conceitos para a clínica, para que a experiência de desvio que ela se propõe a criar seja também uma experiência política, de enfrentamento dos processos de assujeitamento do mundo contemporâneo.

Essa clínica precisa criar um dispositivo que faça desestabilizar as formalizações que o mundo contemporâneo produz. Ao criar formas de ser e de estar no mundo, os processos de subjetivação do mundo contemporâneo produzem diversas formas de sofrimento psíquico.

Na clínica, o processo de desestabilização das amarras existenciais ao qual o sujeito está submetido é feito pela criação de um dispositivo em que seja possível a experimentação do novo. É um espaço de criação mais do que uma formalização, onde o desejo seja visto em sua potencialidade de transformação das formas duras do existir, mais do que em sua negatividade estrutural. A análise deve possibilitar o questionamento das convicções e dos comportamentos repetitivos e engessados, fazendo o sujeito se questionar sobre aquilo que ele acredita que seja seu eu. Assim, ela deve ser um dispositivo de recriação de si e de questionamento sobre as verdades que atravessam, formam e conformam o sujeito.

O sofrimento psíquico, hoje em dia mais do que nunca, é tratado em suas raízes biológicas pela psiquiatria contemporânea. Devido à competência inquestionável de suas formulações teóricas e suas pesquisas científicas, passamos a viver um momento em que todas as respostas parecem ser fundamentadas em problemas estruturais, de ordem biológica. Independentemente de sua eficácia objetiva, seu sistema explicativo do sofrimento psíquico é eficiente em criar novas fórmulas para a felicidade. Com isso cada vez menos se questionam os valores não estritamente orgânicos que também produzem os sintomas. A hegemonia das questões biológicas no saber psiquiátrico se faz evidente nesta espécie de veto silencioso às outras possibilidades de leituras sintomatológicas.

Seguindo este raciocínio, Guattari e Rolnik (1986) apontam que a produção de subjetividade no mundo moderno atual é amarrada por um conjunto de saberes e poderes que eles chamam de economia subjetiva capitalística. Segundo sua perspectiva, a economia simbólica da atualidade produz cada vez mais verdades sobre o sujeito que dependem e derivam não de uma amarragem simbólica parental, mas sim, de uma amarragem mercadológica, em que o Capital, mais do que qualquer força, funda subjetividades, valores e modos de ser no homem. Cada vez mais saberes técnicos - sejam eles médicos, psicológicos, cosméticos ou outros - e seus discursos de verdade invadem a vida cotidiana e aprisionam a experiência subjetiva singular.

As conseqüências disso são: sujeitos culpados, quando cada vez mais se vêem frustrados em atingir suas metas pessoais; segregados, quando se estabelecem normas rígidas do que é ser normal e anormal, sobre ser capaz e não ser capaz; e infantilizados, quando existe todo um discurso científico do que se deve ou não fazer para ser feliz, para ser bem-sucedido, para fazer amigos, etc. Diríamos mais, a experiência do contemporâneo, dentro da organização capitalística, pode ser a experiência da solidão e da falta de acolhimento e de laços sociais duradouros.

A psicanálise, para seguir no mundo contemporâneo, não pode ficar indiferente a isso. Deve, para acompanhar essas mudanças, potencializar sua clínica e não utilizar sua técnica e suas interpretações da mesma forma que um médico prescreve medicamentos. Ela deve ser um espaço de acolhimento da diferença e de encontro. Mais do que 
uma profilaxia adaptativa, a psicanálise deve positivar a criação de novas formas de subjetivação.

Diante do abandono do homem moderno, faz-se necessária a definição de um dispositivo que seja clínico no sentido de ser crítico a todas essas forças, sendo capaz de acolher o indivíduo em sua singularidade, respeitando a riqueza da experiência humana e afirmando a vida. Esse seria um espaço de resistência capaz de disparar mudanças, de questionar valores e criar novos modos de ser e de estar no mundo.

Dizemos com isso que uma interpretação psicanalítica pode estar do lado dessas forças reativas de aprisionamento, que são ortopédicas, mas não dizem muito sobre a real potência das afirmações singulares, que são as forças criativas capazes de produzir o novo.

\section{REFLEXÕES SOBRE A INTERPRETACCÃO PSICANALÍTICA: PENSANDO O POSSIIVEL CAMPO DE EXPERIMENTAÇÃO CLÍNICO}

A interpretação na psicanálise freudiana é o caminho pelo qual o analista desvenda os sentidos latentes das palavras e comportamentos dos sujeitos em análise. Ela tem em vista a produção de sentido sobre os sintomas, apontando o desejo inconsciente, por isso é um dos pilares da técnica, funcionando como um campo discursivo que apontaria para o núcleo do inconsciente e da causação psíquica.

O método psicanalítico fundado na interpretação surge muito cedo na obra de Freud. Desde seus Estudos sobre a Histeria, Freud (1893-1895) já assinalava a ineficácia do método hipnótico e catártico para o tratamento efetivo das neuroses histéricas. Para ele, esses métodos não proporcionavam ao paciente a tomada de consciência dos conteúdos latentes ao discurso, responsáveis pela produção sintomática. Surge então, um novo método investigativo mais capaz de trazer à tona os afetos recalcados causadores dos sintomas: a associação livre.

Assim sendo, Freud resolve com a associação livre o problema de acessar as lembranças inconscientes de seus pacientes, os quais em suas falas lhe traziam inúmeros materiais simbólicos provenientes de suas lembranças e de suas construções fantasiosas, o que lhe possibilitou trabalhar minuciosamente nas causas etiológicas das neuroses através da história de seus pacientes.

Baseado em uma concepção de divisão mental e armado do conceito de inconsciente, Freud fundamentou seu método investigativo na produção de sentidos para o sofrimento psíquico, rompendo com a concepção clássica imperante entre os médicos de seu tempo de uma etiologia orgânica de todas as "doenças dos nervos".

Desde então, o discurso de um paciente acometido de um sofrimento psíquico é entendido como um campo semiótico dotado de profundidades, afirmando a existência de uma transcendência subjetiva capaz de ocultar significações. A fala, assim entendida, torna-se um precipitado de signos que encenam uma forma irreal. Existiria por trás dos signos da fala uma verdade a ser revelada. A realidade da fala estaria oculta em uma verdade subjetiva possível de ser entendida através do método interpretativo.

O tratamento clínico passaria a ser entendido como uma operação de linguagem, mostrando, através da noção de inconsciente, que o aparelho psíquico tinha instâncias que transcendiam ao corpo biológico e eram passíveis de interpretação. O corpo, em Freud, é representável, ou melhor, é passível de ser fantasiado no aparelho psíquico. O desejo seria, portanto, um motor para as fantasias e essas se alimentariam de forças provenientes do corpo. Assim, surge o conceito de pulsão, mostrando que o aparelho psíquico é resultado de inscrições representacionais das pulsões do corpo na psiquê (Garcia-Roza, 1993).

O destino dessas pulsões do corpo seria esbarrar em resistências do aparelho psíquico que procuram torná-lo inoperante. $\mathrm{O}$ recalcamento que funda o aparelho psíquico, segundo Freud, seria relativo aos afetos e pulsões sexuais dirigidos a figuras parentais. Esse seria o momento de fundação da subjetividade, quando o aparelho psíquico se organiza e estabelece suas relações objetais.

Uma análise, dentro dessa concepção, seria uma tentativa de reaver o recalcamento, de rememorar para elaborar os representantes mentais das pulsões inconscientes. Freud afirma em diversos momentos de sua obra que o trabalho psicanalítico consiste na tradução do texto inconsciente para uma fala consciente, decodificada de modo a alcançar a racionalização consciente.

Esse movimento, porém, não era nada fácil, e uma análise teria que lidar com as resistências do sistema psíquico. A resistência ao processo de análise e a direção da cura passariam pelo enfrentamento das forças que impediam as lembranças de se tornarem conscientes, e o instrumento encontrado por Freud para transpor essas forças seria a análise da resistência. As interpretações passam de uma construção triunfante de significações sobre os sintomas para uma análise das resistências, feita primordialmente através de um campo transferencial. 
Seria dentro desse campo que a interpretação funcionaria, dobrando as resistências e resgatando lembranças afetivas que atualizariam o desejo recalcado nele; e a partir da identificação dessa resistência poderia surgir uma interpretação (Birman, 1991)

No final da obra freudiana aparece o conceito de construção em análise. No texto Construções em análise, Freud (1937) ressalta um aspecto das interpretações em análise pouco comentado ao longo de sua obra: seu viés construtivo. Uma análise não seria apenas interpretativa, mas teria como finalidade uma construção do passado esquecido dos pacientes, reconectando fragmentos da história individual a outros fragmentos de memória.

A análise, junto com as interpretações, tentaria reconstruir a história individual do sujeito através de uma arqueologia das representações mentais, que tomariam emprestada a capacidade criadora da interpretação para preencher lacunas das lembranças rememoradas. Uma interpretação ou uma observação qualquer do analista passa a ser entendida nesse momento da obra freudiana como um jogo dialético entre o analista e o paciente.

A confirmação de uma interpretação seria resultante de uma construção simbólica que poderia ou não ser verdadeira. Nesse texto, Freud aponta uma diferenciação dos conceitos de interpretação e construção. O termo interpretação seria mais bem entendido como aquela ação do analista sobre algum material simples que apareceria no discurso do paciente, como um chiste, uma associação ou uma parapraxia (ato falho). Uma construção em análise seria algo mais amplo, seria a reconstrução da história individual do paciente, história que ele havia esquecido e que dizia respeito aos seus sintomas atuais. Ela estaria associada ao elaborar em detrimento do recordar. "O paciente não pode recordar a totalidade do que nela se acha recalcado, e o que não lhe é possível recordar pode ser exatamente a parte essencial." (Freud, 1920, p. 29)

De qualquer forma, Freud, mesmo estabelecendo a construção como substituto do recordar, mantém com ele uma dívida com os estatutos de verdade subjetiva da história individual. Ao refazer a história de seus pacientes ele também fazia a arqueologia das verdades individuais, e então, mesmo aqui, podemos identificar a preocupação freudiana com a busca da verdade do sujeito em análise.

Freud preocupou-se em apontar que todo esse processo nada tinha de sugestão. O manejo do analista seria importantíssimo para fugir da sugestão, ou seja, para uma análise ser fidedigna e realmente revelar as construções desejantes era imprescindível uma boa operação da técnica analítica.

$\mathrm{O}$ ponto de questionamento de toda essa suposição teórica de Freud estaria mais além de suas indagações sobre a direção de uma análise. Seria exatamente onde ele funda sua noção de sujeito que o questionamento da prática clínica da psicanálise freudiana poderia começar.

A constituição subjetiva na teoria freudiana é amarrada por suas suposições sobre sexualidade. Nesta, é fundamentada toda concepção de desejo e vida psíquica e a partir dela surge a noção de complexo de Édipo e sua teoria da castração. Esse conceito, extremamente controverso mesmo entre seus seguidores, sustentava a origem da sexualidade em um conflito entre os investimentos libidinais das crianças em seus pais e a renúncia a esses mesmos sentimentos. Com essa idéia, Freud funda uma concepção de desejo inconsciente baseada na culpa por esses mesmos sentimentos. $\mathrm{O}$ interdito do incesto seria considerado o fator de subjetivação primordial do indivíduo, responsável por sua entrada no universo simbólico do desejo. É claro, isso terá inúmeras conseqüências em sua teoria e nas de seus seguidores, baseando a sexualidade e o desejo por uma renúncia primordial, a teoria se estabelece como regra universal e condição primordial de subjetivação, afirmando o desejo como falta; mais que isso, a renúncia ao incesto seria responsável pela estruturação dos grupos sociais.

Em Totem e Tabu, Freud (1913) reconstrói a origem da civilização por uma mitologia da morte do pai primevo. A mitologia é a seguinte: antes da civilização, indivíduos viviam em bandos, e neles um pai violento guardava todas as fêmeas para si. Os filhos, à medida que cresciam, eram expulsos do território. Em um determinado momento, alguns desses filhos se reuniam e retornavam, matavam e devoravam o pai. Este era temido e odiado, mas também era amado e invejado. Ao devorar o pai, o bando era tomado de horror e culpa, e o pai morto passava a ser mais temido ainda em sua representação simbólica. Como solução para a culpa, o filhos passaram a reverenciar um substituto do pai morto, uma representação totêmica, que proibia o parricídio e incesto. Em psicanálise, os dois desejos recalcados do complexo de Édipo são o parricídio e o incesto. O desejo aparece aqui como uma renúncia de satisfação que permitiria a entrada dos indivíduos no domínio das leis e da linguagem.

Deleuze e Guattari (1976), em O Anti-Édipo, criticam a idéia universalizadora do desejo fundada no drama da tríade familiar. Para eles, essa não é a verdade que funda o desejo, nem o inconsciente. Mais 
ainda: a castração como um desejo universal restringe outras formas de desejo que podem se manifestar. Então, uma psicanálise que viesse a interpelar o sujeito pelo desejo, estaria fadada a mortificar outras manifestações desejantes também muito importantes para a constituição da subjetividade. Essa visão rompe com a naturalização de um tipo específico de desejo fundamentado na castração para mostrar que, se existe um complexo de Édipo, ele é produto de um evento coletivo. Esse pensamento questiona a intimização do desejo e mostra seu caráter múltiplo, produto de um campo semiótico social. Desde sua obra Vigiar $e$ Punir (2003), Foucault tenta também demonstrar que essa intimização de si, ocorrida com o advento da modernidade, funcionava como um dispositivo de saber-poder de individuação que despotencializava as instâncias coletivas da sociedade.

Desta forma, poderíamos sublinhar que a técnica psicanalítica e sua produção discursiva estariam fundamentadas em uma visão intimista do sujeito, privilegiando o individual em detrimento do coletivo. Os fundamentos da psicanálise herdam da prática do confessionário seu olhar sobre o desejo e este olhar para si próprio. Colocar em palavras os meandros do desejo em relação com a proibição, com o pecado e a culpa, é também a matriz dos conceitos fundamentais da psicanálise freudiana.

Acrescentemos a isso o próprio problema da interpretação que atravessa a prática psicanalítica como atividade hegemônica que se instaura entre analista e paciente. $\mathrm{O}$ próprio da interpretação se fundamenta em um mecanismo de poder que restringe as possibilidades da ação. A interpretação é uma prática que delega ao analista, através do manejo clínico, a tarefa de apresentar sentido ao material manifestado pelo seu paciente. Seria uma prática de recorte e de sistematização deste material.

Através disso, poderíamos nos indagar: a psicanálise seria uma prática de engessamento de sujeitos, de naturalização de formas subjetivas formatadas em um "eu" invariante a serviço das forças instituídas do capitalismo?

O dispositivo psicanalítico nasceu quando Freud resolveu criar um espaço de acolhimento para suas pacientes histéricas. Ele percebeu em sua clínica que elas desejavam ser escutadas. Além disso, queriam dar sentido às suas agruras psíquicas através da fala. Foi o que Freud fez. O método da associação livre foi estabelecido com o intuito de liberar a fala da histérica do aprisionamento explicativo das neuroses ao âmbito puramente biológico. Freud demonstra com seus estudos que o aparelho psíquico estaria além do corpo biológico. Ele poderia ser representado de maneira transcendente ao corpo, e essas representações do corpo seriam passíveis de interpretação. Essa interpretação, ao liberar seus pacientes à fala, os aprisionou a uma prática de inteligibilidade e a um discurso de saber assujeitador.

Não obstante, o campo de experimentação da clínica foi sendo modificado ao longo da obra, e da primeira tópica até a segunda, muito de seu método analítico se modifica. Se na primeira tópica o método da associação livre e a tomada de consciência eram predominantes, com a segunda tópica, junto com o surgimento de conceitos como masoquismo, pulsão de morte, castração, resistência, compulsão à repetição, etc., a clínica freudiana aponta o tempo todo para uma construção teórica baseada em pressupostos que indicam a constituição da vida psíquica pela falta.

$\mathrm{Na}$ ânsia por desenvolver um sistema explicativo para a psiquê humana, Freud acabou impedindo seus pacientes de falarem livremente. Se eles falavam, falavam sob as condições do método interpretativo de Freud e sob as rédeas de sua mitologia interpretativa. Esse era o discurso das análises freudianas e também de seus seguidores mais diretos. Era o caso, por exemplo, de M. Klein, que foi muito criticada por seu método interpretativo avassalador. Deleuze escreve sobre o método kleiniano no texto Psicanálise Morta Análise o seguinte:

Deixa-se psicanalisar, acredita-se falar e aceita-se pagar por essa crença. Mas não se têm a menor chance de falar. A psicanálise é toda feita para impedir as pessoas de falarem e para retirar todas as condições de enunciação verdadeira. (...). É assombroso. Os dois textos maiores sobre isso são o pequeno Hans, de Freud e o pequeno Richard, Melanie Klein. É um forcing incrível, como uma luta de boxe por demais desiguais. Humor de Richard, no início que zomba de Melanie Klein. (...) Insensível e surda, impermeável, a senhora K. vai quebrar a força do pequeno Richard. Leitmotiv do livro no próprio texto: a senhora $\mathrm{K}$. interpretou, a senhora $\mathrm{K}$. interpretou, a senhora K. INTERPRETOU. (Deleuze, 1998, p. 96-97)

Deleuze critica e ironiza veementemente, nessa passagem, a amarragem simbólica das interpretações kleinianas, e sua luta com seus pacientes para se fazer entender. Em A ordem dos discursos, Foucault (1996) apresenta os mecanismos que rarefazem e controlam os discursos. Poderíamos, junto com ele, afirmar que a psicanálise com suas categorias universais poderia vir a ser uma prática que engessa a relação com o paciente pelo 
uso da interpretação que é direcionada por seu manancial teórico-discursivo. Este método possibilita cortes sistemáticos na fala do paciente, impondo um discurso de outra ordem à fala e à inquietação do sujeito. Isso ocorre pelo ímpeto psicanalítico de encontrar substratos infantis nos comportamentos repetitivos atuados. Assim, através da interpretação, o analista procura e acha, ou melhor, procura e impõe aquilo que já supunha encontrar. Daí o perigo da prática cega da interpretação encontrada neste trecho crítico sobre o trabalho clínico de M. Klein. Ela territorializa o desejo. Será justamente por isso que Deleuze (1998) afirma ser Freud um romano, pois a interpretação é um mecanismo de poder que territorializa o desejo. Descobrir aqui seria sinônimo de conquistar um território. Deste modo, podemos afirmar que o método interpretativo aqui criticado baseia-se em uma determinada concepção de inconsciente e de processos de subjetivação. $\mathrm{O}$ inconsciente como produto do recalcamento e como precipitado de representações e imagens, é pensado como um universal, e nessas análises é tratado como um absoluto do sujeito, que estaria atrelado a uma única amarragem simbólica fundadora da subjetividade: a castração.

Dentro da perspectiva lacaniana, a dinâmica inconsciente é regida pela lógica lingüística. Nessa teoria, o desejo seria algo estático, proveniente de fantasias estruturadas por um conjunto de signos e regras de linguagem passíveis de interpretação.

$\mathrm{O}$ inconsciente seria entendido como um campo de onde o tempo está excluído. Para Lacan, o momento da entrada na linguagem é o da escolha sintomática. Essa escolha estrutural é rígida, não apresentando grandes mudanças. Disso decorre uma clínica dos diagnósticos estruturais à qual o sujeito não escapa. A clínica se fundamentará por uma direção dada pelo analista ao identificar o sintoma estrutural, seja ele histérico, perverso, psicótico ou obsessivo (Quinet, 1997).

A mudança em uma análise se daria no nível dos significantes representantes dessa estrutura. A entrada no universo simbólico da cultura só seria possível por uma mediação lingüística transcendente, fundadora de uma concepção de subjetividade estruturada pela falta.

A relação do analista com o paciente, também, aqui, fundamenta-se em jogos intersubjetivos de verdade, sendo a única verdade a falta estrutural do sujeito. Na técnica lacaniana, a verdade do sujeito é a do momento presente, e é no campo transferencial que emerge o discurso do sujeito, sendo a interpretação uma construção de dentro desse campo.

A teoria lacaniana critica algumas posições que estabelecem o inconsciente em sua perspectiva ontológica. O inconsciente não é um ser, ele é ético, produto da relação intersubjetiva entre analista e analisando. Está na superfície da relação entre esses dois seres que se encontram no processo analítico; mas de qualquer modo, a perspectiva ética do inconsciente não o livra de uma ontologia do furo da linguagem. Se a linguagem não permite dizer tudo, se sempre falta algo a ser dito, o ser da linguagem é o negativo.

A clínica, de acordo com essa teoria, é baseada em um tempo que não é cronológico, mas lógico, regido pelas regras determinadoras da linguagem. Assim também funciona o ato analítico enquanto função de interpretação. Ele serve à produção de sentido dada pelo paciente. $\mathrm{O}$ analista não empresta sentido, ele é o facilitador, em sua posição de falta a ser, do desfile do significante que nunca cessa de se produzir.

Não obstante, se fazemos essa crítica aos universais da forma e da linguagem, e da afirmação do impossível e da negatividade do desejo, como podemos pensar um desvio possível ao formalismo e em relação às leis universais?

O nascimento do discurso moderno e a concepção de homem que dele advém, longe de promover a liberação do sujeito, enclausura-o em um aparato de discursos com estatuto de verdade, capazes de naturalizar formas de ser, além de engessar e constituir formas de agir e pensar.

A psicanálise seria, ela também, um discurso sobre a verdade do sujeito, e entraria dentro do aparato regulamentador da sociedade quando se propõe a utilizar seu método na produção de um saber individualizador. Dando sentido e significando de acordo com regras estabelecidas que conduzam ao conhecimento, e com seu discurso, a psicanálise corre o risco de calar o paciente e de a ele dirigir um aparato de significação que nada tem de libertador. $\mathrm{O}$ poder do dispositivo analítico deve ser levado em consideração sempre que implementamos uma crítica a seu sistema de saber-poder.

Sendo assim, as relações de poder que se espalham pela sociedade não caminham em sentido único. Elas são o resultado de um equilíbrio de forças. Em $O$ sujeito e o poder, Foucault (1995) mostra a dimensão produtiva das relações de poder e como os processos de subjetivação resultam também de uma resistência às formas duras das instituições sociais. A subjetivação é, portanto, um campo de combate onde existem tanto forças assujeitadoras como forças de libertação. É nas forças de libertação que podemos identificar novas formas de subjetivação, onde o poder produz uma fuga, um "fora" do sistema de poder. $\mathrm{O}$ fora do poder é o momento de ruptura com os instituídos que regulam os modos de ser e naturalizam práticas sociais. Há nas relações de poder, portanto, 
linhas de força capazes de fazer valer desvios dos instituídos capazes de afirmar a diferença.

Assim, os processos de subjetivação são de ordem coletiva, engendrando sujeitos que não são, de forma nenhuma, estáticos. O sujeito não possui uma natureza nem uma essência. Ele é constituído historicamente e é resultado de um campo de forças sociais que se dobram, produzindo tanto interioridades como exterioridades. A subjetividade é algo que se produz, é uma positividade das relações de poder inerentes ao campo social, e se o poder está em todo lugar, é a partir dele que as resistências são possíveis.

Assim, pensar a clínica é pensar na política à qual ela está relacionada, as forças coletivas a que ela se conecta, para fazermos dela um espaço crítico, um lugar onde possa existir o não-formal, onde resistências e estratégias de enfrentamento das forças aprisionantes da vida possam ser constituídas. Uma clínica não está desconectada de uma crítica das forças engendradoras de subjetivação. É então um lugar de afirmação da vida. Por isso a clínica pode ser entendida como um campo de experimentação e da afirmação de modos de ser e de estar no mundo, onde o sujeito é levado a questionar-se sobre as verdades que o atravessam e o constituem. A clínica deve ser um espaço de experimentação onde as verdades instituídas são apontadas por um questionamento incisivo que possa não impor o silêncio da verdade, mas a inquietação do questionamento que celebra a vida.

\section{CONCLUSÃO}

No decorrer do presente artigo, analisamos o papel preponderante do método interpretativo na prática psicanalítica, salientando sua relação com a invenção de verdades subjetivas e teóricas. Desta maneira, apontamos como a interpretação se instaura através de relações de poder que visam a engessar a fala do paciente em verdades enquadradas pelo próprio manancial conceitual da psicanálise. No entanto, mostramos que a clínica pode ser um espaço eminente de questionamento de verdades instituídas, de comportamentos e de convicções engessadas por certos modos de existir que submetem o homem moderno ao sofrimento psíquico. A clínica psicanalítica, pelo meio de uma crítica interna às vicissitudes do método interpretativo, deve explorar o campo clínico como espaço de experimentação e de questionamento de si mesma. A clínica pode se desvencilhar das amarras da interpretação e resistir assim à hegemonia que o próprio papel da interpretação tomou em sua prática.

\section{REFERÊNCIAS}

Birman, J. (1991). Freud e a interpretação psicanalítica. Rio de Janeiro: Relume-Dumará.

Deleuze, G., \& Guattari, F. (1976). O Anti-Édipo: capitalismo $e$ esquizofrenia. Rio de Janeiro: Imago.

Deleuze, G., \& Parnet, C. (1998). Diálogos (E. Ribeiro Trad.). São Paulo: Escuta.

Foucault, M. (1995). O sujeito e o poder. Em R. Dreyfus, Michel Foucault, uma trajetória filosófica (V. P. Carreiro Trad., pp. 231249). Rio de Janeiro: Forense.

Foucault, M. (1996). A ordem do discurso. (L. Sampaio Trad.). São Paulo: Edições Loyola.

Foucault, M. (2003). Vigiar e Punir: nascimento da prisão (R. Ramalhete Trad., 27ảed.). Petrópolis: Vozes

Freud, S. (1893-1895/1987). Estudos sobre a Histeria. Em Edição standard brasileira das obras psicológicas completas de Sigmund Freud (2ªd., Vol. 2, pp. 13-316). Rio de Janeiro: Imago.

Freud, S. (1900/1987). A interpretação dos sonhos. Em Edição standard brasileira das obras psicológicas completas de Sigmund Freud (2aed., Vol. 4,5, 13-700). Rio de Janeiro: Imago.

Freud, S. (1913/ 1987). Totem e Tabu. Em Edição standard brasileira das obras psicológicas completas de Sigmund Freud ( 2 aed., Vol. 23, pp. 13-162). Rio de Janeiro: Imago.

Freud, S. (1920/1987). Além do princípio do prazer. Em Edição standard brasileira das obras psicológicas completas de Sigmund Freud (2aed., Vol.18, 13-77). Rio de Janeiro: Imago.

Freud, S. (1915/1987). O Inconsciente. Em Edição standard brasileira das obras psicológicas completas de Sigmund Freud ( $2^{\mathrm{a} e d .,}$ Vol.14, pp. 165-223). Rio de Janeiro: Imago.

Freud, S. (1937/1987). Construções em análise. Em Edição standard brasileira das obras psicológicas completas de Sigmund Freud (2. ed., Vol.23, pp. 275-289.). Rio de Janeiro: Imago.

Garcia-Roza, L. A. (1993). Introdução à metapsicologia freudiana. Rio de Janeiro, Zahar.

Guattari, F., \& Rolnik, S. (1986). Micropolítica. Cartografias do desejo. Petrópolis, Vozes.

Lacan, J. (1996). O Seminário, livro 1 - Os escritos técnicos de Freud. Rio de Janeiro. Zahar.

Quinet, A., (1997). As 4+1 condições da análise. Rio de Janeiro. Zahar.

Recebido em 14/06/2007 Aceito em 05/05/2008

Endereço para correspondência : Leonardo Pinto de Almeida, Rua Oswaldo Cruz, 28/701, Icaraí, CEP 24230210, Niterói-RJ, Brasil.E-mail: tazaime@hotmail.com 